\title{
The Effect of Cooperative Learning Strategies on Iranian Intermediate Students' Writing Achievement
}

\author{
Nahid Ahmadi, Khalil Motallebzade, Mohammad Ali Fatemi \\ Department of English, Islamic Azad University, Torbat-e-Heydareih Branch, Torbat-e-Heydareih, Iran \\ Email: nahmadi60@yahoo.com, Kimia1010@yahoo.com, kmotallebz@gmail.com, fatemi35@gmail.com
}

Received 9 November 2014; revised 13 December 2014; accepted 28 December 2014

Copyright (C) 2014 by authors and OALib.

This work is licensed under the Creative Commons Attribution International License (CC BY). http://creativecommons.org/licenses/by/4.0/

(c) (i) Open Access

\section{Abstract}

The present study investigated the effect of cooperative learning strategies on Iranian intermediate students' writing achievement. The researchers selected 83 English students in Khorasgan Islamic Azad University. The researcher assigned Oxford Placement Test by [1] test with 100 multiple choice questions as the homogeneity test and selected 60 students and divided them equally as the experimental and control groups to teach them how to write TOEFL essays in cooperative and traditional ways. Based on a pretest-posttest experimental design, the students wrote two different essays at the first and the last sessions of the study as the pretest and posttest and the results were analyzed. The findings of the writings revealed a statistically significant difference $[t(58)=15.748, p=0.000]$ between experimental $(M=92.97, S D=1.752)$ and control $(M=80.20$, $\mathrm{SD}=4.080$ ) groups with writing ability. Accordingly, the data obtained from the findings indicated the experimental (cooperative) group's better performance. Therefore, the null hypothesis was rejected by the results of the study.

\section{Keywords}

Peer Tutoring, Cooperative Projects, Jigsaw, Positive Interdependence, Individual

Subject Areas: Education, Linguistics

\section{Introduction}

English writing plays a prominent role in English language writing. Since there is a very close relationship between writing and thinking [2], it is a valuable and important part of any language course. A factor that seems to be very clear about writing and speaking is the way and the process chosen and used by the writers or speakers for transferring their message. The final product shows the writer's ability in doing his duty which is writing a 
good and qualified text. He has enough time to change and modify it in the planning and drafting processes before presenting the final product. This process is what the professional and in fact successful speakers do. They try to reduce their speech errors by planning and drafting before presenting it. This is one of the factors that make learning the writing skills more important and vital for those foreign language learners who want to use it in different circumstances to show their language skills and attract more and more addressees from listeners to readers.

The salient role and duty of a good writer is to predict the situation in which his message is going to be transferred and try to imagine about the particular readers who are going to receive his message. When a writer pays attention to the principles of the writing skill and applies them in a correct manner, consequently the message ambiguity is reduced and its comprehensibility is increased. It seems that this is the major problem for students in writing a passage especially in a foreign language.

"Cooperative learning is a strategy which is based on the psychological aspects of cooperation and competition for learning. It mainly refers to the techniques in which students work in separate small groups or teams. In this way, they can help each other directly to master various academic materials being taught by their teacher. In fact, the teammates apply a variety of learning activities to improve their understanding of a subject. Each member of a team is responsible for learning the taught material and for helping teammates learn and thus creating atmosphere of achievement” [3].

Writing is a contextualized activity and contains three elements: the writer, the reader and the texts that are basically interacted to each other and can represent in various knowledge genres and different skills. "Collaborative writing" involves developing instructional arrangements whereby, adolescents work together to plan, draft, revise, and edit their compositions [4]. In contrast with mere traditional methods, this is a technique that sees the English classes as the learner-centered structures and the teachers do not have salient roles for choosing and applying different activities for learning and doing exercises. Graham \& Perin believe that cooperative writing shows a strong impact on improving the quality of participants' writing skills [5].

Collaborative writing is a sub-group of cooperative learning which has different approaches. The approaches of CL by Smith B. L. \& MacGregor, J. T. [6] consist of, for example, problem-centered instruction, writing groups, peer teaching, discussion groups and seminars, and learning communities. This kind of learning seems to have different forms that teachers try to apply them based on their own background, previous experiences and teaching methods.

\subsection{Statement of the Problem}

As Rivers [7] mentions with so much writing in foreign language classes over so many years one would expect to find highly effective methods for teaching writing skill and marked success in learning it. There are many students in different levels, from school students to college ones who have studied English as a foreign language for years and are in intermediate, upper-intermediate and advanced levels but can not talk about particular subjects, fields, and even themselves correctly in writing. This is not the case for those who use the foreign language for their job. Of course, these students follow some particular rules or format for business letters, reports or other kinds of business written texts and they, mainly, keep a format and just change the needed words for a particular passage.

The principles, rules, and factors related to the characteristics of both writing and speaking or each of them separately make students pay more attention about how to apply them carefully and correctly in order to have a satisfactory product especially in writing because the final product shows the writer' abilities and knowledge in presenting a message. This leads them to test different learning methods and approaches in order to learn a skill more effectively. It is basically the teachers' duty to choose a beneficial method with various and suitable activities for teaching a skill for students to help them learn it better and apply it in different situations.

Also, a lot of students wish highly to learn some skills such as writing perfectly or in an acceptable level, but they do not have enough motivation to study about that and look for their weak points and shortcomings in order to remove them. They just wish or need to learn this skill but they know it takes a lot of time to study it individually in order to use it practically with the least mistakes or errors. They need some more help from others from good books, teachers, other skillful students or other accessible resources. In a study by Mandal [3], it is claimed by the researchers that cooperative learning can reach this goal because in comparison with other kinds of learning methods, it has some significant advantages for students with different levels of proficiency. 


\subsection{Significance of the Study}

In cooperative leaning and subsequently in cooperative writing, since the students' goal is the same and they write the same text altogether, they try to use all of their knowledge and abilities to do their best and present their best writing as a final product. The students in each group have access to other members of groups' mind and follow their goals collaboratively. The teacher is not omitted or excluded from the members of the groups. He can be a pair or a member in all of the groups to help student to remove their shortcomings or add some strong points that they have forgotten to consider. The main role of collaborative learning is to ask students to write a unique text with the help of other members of their group. In this way, all the members of the group are responsible for the final product not an individual student. Harmer [8] claims "for these reasons, collaborative writing has a strong power to foster writing habit in a unique way in all groups or teams."

There are many activities that are related to the collaborative learning and can be used in the cooperative writing too. From all of them, two activities are more salient and practical which are: using the board and writing in groups and pairs. The former is used mainly for teaching and learning such as 1) individual sentences and 2) dictogloss. But the latter is used for writing texts such as 1) rewriting and expanding sentences, 2) looking at first and last lines of a story or happening (to extract students' imagination), 3) applying directions, rules, and instruction and finally, 4) using story reconstruction.

So, each of group members is responsible to study about the part that has been chosen for them to do completely or at least acceptably. In these conditions, it is better to use jigsaw activity in which each member is assigned some material to learn by the teacher's help and teaching or by studying themselves and to teach to his group members.

The significance of using cooperative learning in different classes may lead to various strategies and activities. Cooperative learning (CL) activities can be used by teachers to provide students opportunities to practice new skills and concepts. By certain activities, teachers can help students make "connections between the concrete and abstract level of instruction through peer interactions and carefully designed activities" [9]. Apple \& Shimo [10] add CL activities also show that each group members has a specific role, and if each one of them does not fulfill his or her roles, the effort of the group does not lead to its final goal.

Collaborative skills are in fact those skills which require to be worked together not by each student individually. Some of the skills needed for successful collaboration are: "checking that others understand, asking for and giving reasons; disagreeing politely and responding politely to disagreement and encouraging others to participate and responding to encouragement to participate". On page 99 Jacbs \& Hannah [11] refer to the matter that some students may lack these skills themselves, or the language needed using the skills or a combination of both.

\section{Review of Literature}

According to Bowker [12], writing is a skill that is required in many formal and informal contexts throughout life and Richmond [13] refers to it as a continuous process, not an instantaneous activity. Students, for centuries, have practiced these skills in their classrooms. The approach of learning writing skill does not relate just to the first language and has transferred to the foreign language learning too. It does not consider whether it is appropriate for the students who are not professional enough in spoken yet or not. Writing exercises keep students busy and out of mischief (p. 291) [7]. Of course, based on Onozava, 2010 [14], "L2 (second language) writing did not attract much attention until the 1960s; however, writing has been getting more attention recently and its importance in learning a foreign or second language has been understood” (p. 153). He discusses about the importance of the writing skill and learning it which is necessary in schools and in our daily life.

"One of the main reasons that teaching writing is so different from teaching speech is that the two types of discourse differ in some basic characteristics or rules” (p. 159) [15]. He outlines the differences between written and spoken discourses in the following characteristics: 1) permanence, 2) explicitness, 3) density, 4) detachment, 5) organization and slowness of production, 6) speed of reception, 7) standard language, 8) a learnt skill, 9) sheer amount and 10) importance.

Based on Harmer studies [8], there are a number of approaches to the writing skills which are about the practice of this prominent skill inside and outside the classroom environment. Hadely [16] refers to approaches of teaching writing in a different categorization such as product approach, process approach, social-constructionist approach, genre approach, creative writing, writing as a cooperative activity, writing-for-learning, and writing- 
for-writing. "Cooperative writing works well whether the focus is on the writing process or on genre study". Harmer, [8] claims that both teachers and students can take advantage of taking part in groups to do class activities such as writing in a cooperative environment”. Working in groups as a cooperative activity can be motivating for students in many parts such as research, discussion, peer evaluation and writing. Sometimes writing instruction may occur in small groups with a teacher or teaching assistant. Small group instruction helps children who may need extra attention develop strategies needed to become independent writers [17].

Cooperative learning is a structural and systematic strategy which is famous in Europe and US [18] and follows a method in which students are assigned into different groups, work together and encourage each other's learning and achievement and finally improve their learning effectiveness. Since scholars have found many good results about the effects of cooperative learning, many models have been developed by researchers that have some main common characteristics (p. 289): heterogeneous students, individual accountability, group-processing, collaborative social interpersonal skills, face-to-face interaction, and positive interdependence. In fact, Bowen [19] mentions to the matter that cooperative learning has been defined differently by different researchers and theorists such as Abdulkarim \& AlJadiry [20] in different models which one of the most famous models is Johnson and Johnson's.

Based on a study [21], both students and teachers have some particular roles in cooperative learning and then cooperative writing. They outline the teachers' roles in six main categories with two sub-categories in each group that represent twelve roles for the teachers (pp. 7-14): the information provider (the lecturer \& the clinical and practical teacher), the role model (the on-the-job model \& the role model as a teacher), the facilitator (the learning facilitator \& the mentor), the assessor (the student assessor $\&$ the curriculum assessor), the planner (the curriculum planner \& the course planner), and the resource developer (the resource material creator $\&$ the study guide producer).

There are many potential roles for the students too, but the most common role include [10] and [22]: "facilitator-a person responsible for ensuring that the group stays on task, recorder-a person responsible for writing down group answers and decisions, summarizer - a person responsible for summarizing the group answers, reporter-a person responsible for conveying the group's ideas to another group, time-keeper-a person responsible for checking the time left to finish the task" (p. 75).

Compared with traditional teaching methods, the cooperative learning groups have some characteristics which are different from traditional groups. Chauhan \& Yadac [23] refer to these differences into two different categories (p. 273). Based on their categorization, traditional learning groups have a kind of "low interdependence; the members take responsibility only for themselves not the other members; the focus is on individual performance only not the group performance; there is individual accountability only; assignments are discussed with little commitment to each other's learning not a vast commitment; teamwork skills are indirectly taught; the leader is appointed to direct member's participation; there is no group processing of the quality of its work; individual accomplishments are rewarded; there is more prejudice, stereotyped, escapists and withdrawal/absenteeism from the situation".

Hassaskhah [24] refers to "cooperation" as the key to cooperative learning. She states that cooperation is a structure of the interactions existed between group members which facilitate "the accomplishment of a specific end product or goal achieved through people working together in groups" (p. 75).

Writing is considered, in fact, as a highly productive skill and actually the most difficult of the four language skills [25]. Collaborative writing involves "developing instructional arrangements whereby adolescents work together to plan, draft, revise, and edit their compositions. It shows a strong impact on improving the quality of students' writing" [5].

According to Oskoz's research into collaborative writing [26], both in the first language (L1) and second language (L2) has shown that this pedagogical approach has great potential and important effects on learning mastering this skill.

\section{Method}

\subsection{Participants}

The study was conducted on about 60 Iranian EFL students aged 18 - 26, with the mean age of 22. They were selected from 83 college students in Khorasgan Islamic Azad University and had passed the related courses of grammar. All the participants' first language was Persian. These students were living in Isfahan at the time of the 
study and did not have any particular contact with English as a second language or any English people around them. Their main experience of writing was limited to the writing paragraphs or summaries. The selection of 60 participants of this 83 college students was based on the result of the Oxford Placement Test (OPT)'s administration as the homogeneity test. Since the number of participants in each group should be at least 25 and during the study, some of them may leave the study, accordingly, students were divided into two groups, the control group and the experimental one, with 30 subjects in each.

\subsection{Instruments}

To determine the effect of cooperative learning on the intermediate students' writing achievement, the following instruments were employed in the present study:

Homogeneity Test the Oxford Placement Test [1] which was applied to ensure the researchers of the level of participants' language proficiency for taking part in the study. It consisted of 100 grammar and vocabulary items and the passing point was 70 . The participants had 75 minutes to answer this multiple-choice test. The researchers presented a pilot test for 45 students to estimate the reliability. The results showed 7.7 by Cronbach Alpha which was an accepted reliability for the OPT. The instructions were read in Persian orally to the participants to remove any problem that they could face.

Pretest was, in fact, an in-class essay which students wrote in the first session about unique subjects for both groups. They had 45 - 60 minutes to write the essay. The essays should contain 250 - 300 words. The students were assigned two topics to choose one arbitrarily and write about. The topics were of the "explaining" and the "preference" type: 1) what are some of the qualities of a good parent? Use specific details and examples to explain your answer; and 2) some people prefer to live in a small town. Others prefer to live in a big city. Which place would you prefer to live in? Use specific reasons and details to support your answer.

Posttest was, in fact, the last essay which students wrote in the last session of the study about unique subjects for both groups with the same period of time like the pretest. They were given 45 - 60 minutes to write the essay. The essays should contain 250 - 300 words. The students were assigned two topics to choose one arbitrarily and write about. The topics were of the "explaining" and the "comparing" types: 1) choose one of the following transportation vehicles and explain why you think it has changed people's lives: automobiles, bicycles, or airplanes; and 2) some people prefer to live in a traditional house but others prefer to live in a modern apartment building. Which one do you prefer? Use specific reasons and details to support your choice.

\subsection{Procedure}

To accomplish the purpose of the study, the following research question was posed:

Q. Do cooperative learning strategies have any effect on Iranian intermediate students' writing skill? To come up with reasonable results on the basis of the research question, the following null hypothesis was proposed:

$\mathrm{H}$. Cooperative learning strategies has no positive or negative effect on intermediate students' writing skill.

To reach the sufficient results, the following procedures were presented:

The researchers applied a pretest-posttest experimental design in which they provided the Oxford Placement Test (OPT) for about 83 students who volunteered to take part in the writing TOEFL essays. The passing point was 70 . The students who got grade 70 were assumed to be proficient enough to enroll in the study. Those students who got the grades higher than 85 were assumed to be more proficient students. After the final and random choosing the study participants and since the study was on the basis that there should be at least one more proficient student in each group, these students were placed randomly in the groups to follow the base of heterogeneity of them. It does not mean that in each group may not be two strong students. In fact the basis is that there should be at least on strong student in each group that is the teacher's responsibility to put them in the groups. Other students can be chosen randomly. The rationale was that all of them had some practice in writing paragraphs and summaries. However, this test was for being sure that they were homogeneous in two major factors such as grammar and vocabulary that were essential for a good writing. However, they were going to learn other factors of writing during this process to be good writers.

From those who passed the test, 60 students (scores 70 and above that) were selected and were divided into two groups (control group and experimental group) in each 30 students. The result of just this number of students' achievement were used and calculated. The students supposed that they were taking part in a learning-towrite period to learn "how to write TOEFL essays"; therefore, they did not know that they were under the inves- 
tigation. Since the participants were taught writing TOEFL essays volunteerily during a particular semisterm, the real sample was 60 students that the researcher knew, not all the 83 students. The purpose of this study was that students write some passages. The teachers were different who taught writing in different methods (the control group's teacher taught writing traditionally and the experimental group's teacher taught writing cooperatively) but the elements of their lesson plan and the materials taught were the same. None of the teachers could teach any material more than the other class. They just had different strategies in teaching writing, doing the writing task in the class, giving the comments to the students, replying the students' problems and the kind of relationship with their students.

In the first session, the participants in both groups were asked to write an essay about the same subject. This in-class essay, which was written in 60 minutes, was assumed as the pretest. The papers were collected by the teacher to be corrected in order to determine the number and the kind of the errors and the amount of proficiency they had over writing.

After pretest, before beginning the treatment, the participants in the experimental group were divided in seven groups (four participants in each group and two participants left). Group working was one of the parts of the cooperative learning. The teacher tried to put at least a more proficient and stronger student who had the grade 85 or higher in each group. Since the students worked in groups to accomplish their work, they tried to help each other by paying attention to the words, sentences, paragraphs, or the whole passage they wrote based on their own knowledge. When they tried to write a draft and represent the final piece of writing, they consulted with each other and provided the last draft. However, there might be students who were active in both or none of them. When they tried to write a draft and represented the final piece of writing, they consulted with each other and provided the last draft. In this way, even the students who were poor in some parts could learn from other student and review the subjects they knew and had learned before.

The techniques used in the experimental group were: using the board, dictogloss, writing in groups and pairs, and first lines \& last lines. These techniques made them to work cooperatively not individually and write thir last writing with the help of other members of their own group.

Although the styles of teaching how to write TOEFL essays were different in each group, the scoring style was the same and based on the basic elements and factors of TOEFL essays [27].

\section{Results and Discussions}

An efficient way for teaching cooperatively was to have a group of students which receive some major strategies related to cooperative learning, to determine the amount of its participants' achievement in writing TOEFL essays, and to compare the results with the amount of its participants' achievement who receive traditional strategies in writing. In order to find the answer to the research question raised and to analyze and interpret the gathered data, some certain statistical processes were performed.

The data obtained from the participants' writings in both experimental and control groups for the pretest changed into the scores by two raters. The data were divided into two parts. One of the parts related to the kind and amount of errors the participants had in their writings. The researcher assigned score 20 for them. This part was a main sub-part of the other part which was related to determining the basic elements and factors of TOEFL essays [27]. The researchers assigned six as the final score for considering all of these factors as a whole. The total score was considered six.

Score six showed that the writer had very strong organizational, structural, and grammatical skills. Score five showed that the writer had good organizational, structural, and grammatical skills. However, the essay contained some errors. Score four showed that the writer had adequate organizational, structural, and grammatical skills. The essay contained a number of errors. Score three showed that the writer showed evidence of organizational, structural, and grammatical skills that still need to be improved. Score two showed that the writer showed a minimal ability to convey ideas in written English. Score one showed that the writer was not capable of conveying ideas in written English.

As Table 1 shows, the independent-samples t-test was conducted to compare the results of the pretest for the participants of both control and experimental group. There was no significant difference in scores of control group $[(\mathrm{M}=48, \mathrm{SD}=2.948)]$ and scores of experimental group, $[\mathrm{M}=48.87, \mathrm{SD}=3.893 ; \mathrm{t}(58)=0.972, p=$ 0.335]. The results of Table 2 confirmed the homogeneity of the participants at the outset of the study.

The data obtained from the participants' writings in both experimental and control groups for the post-test changed into the scores by two raters. 
Table 1. Results for independent samples t-test for writing scores in pre-test.

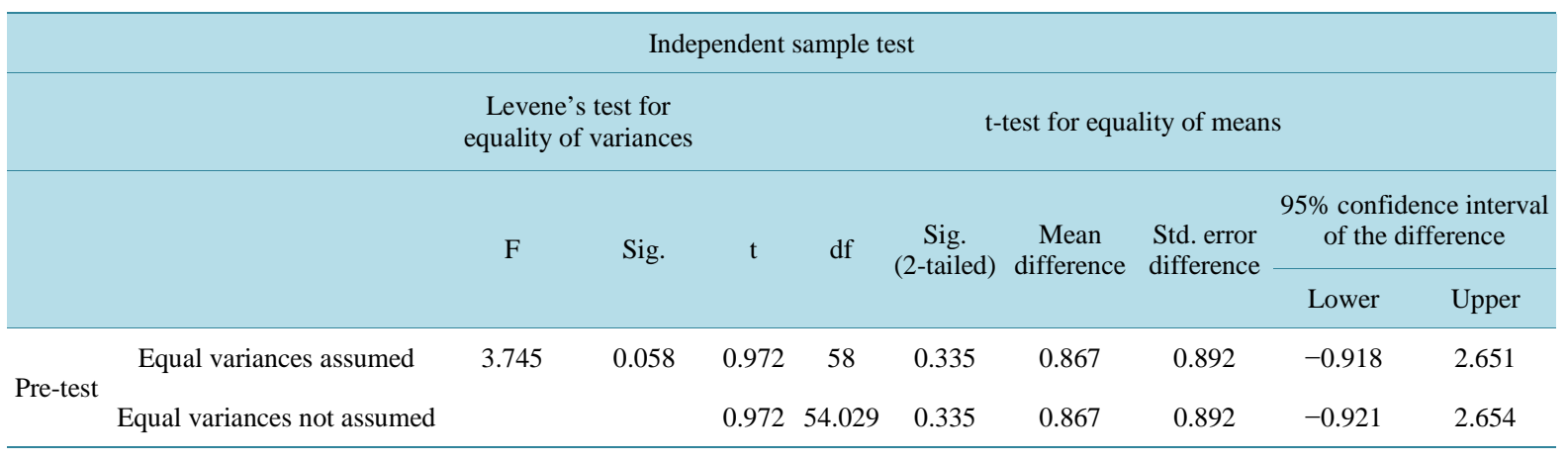

Table 2. Results for independent samples t-test for writing scores in post-test.

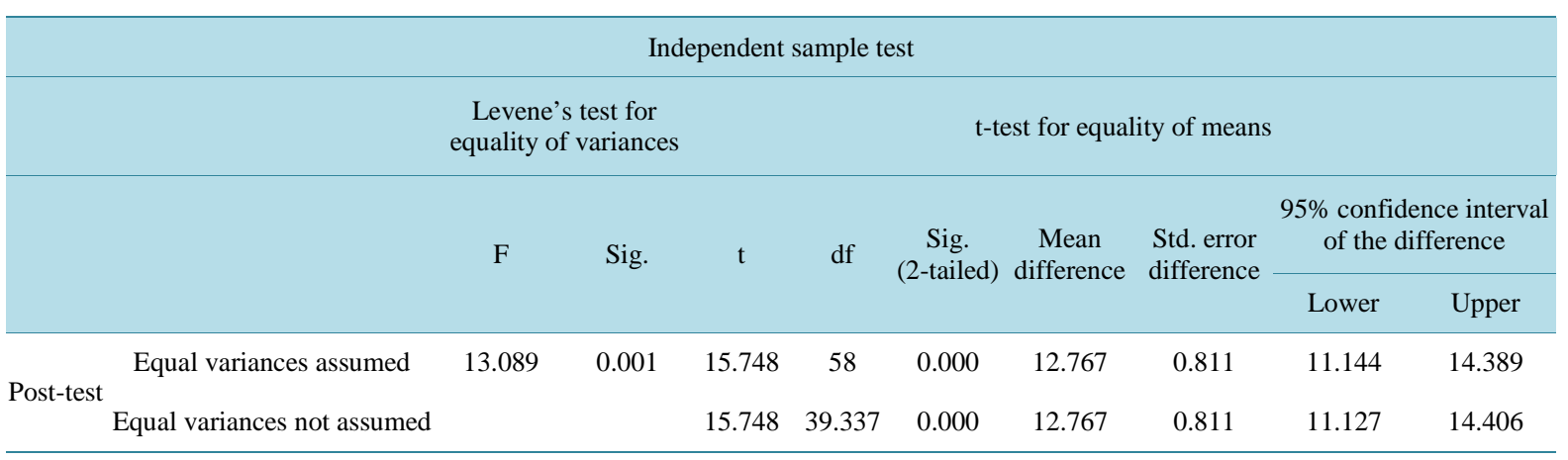

Since the test was not a complete TOEFL test to represent all the participants' skills such reading, listening and speaking, the total score was considered six to represent both qualitative and quantitative data.

The independent-samples t-test was conducted to compare the results of the post-test for the participants of both control and experimental group. As the results of Table 2 show, there was a statistically significant difference $[\mathrm{t}(58)$ $=15.748, p=0.000]$ between experimental $[(\mathrm{M}=92.97, \mathrm{SD}=1.752)]$ and control $[(\mathrm{M}=80.20, \mathrm{SD}=4.080)]$ groups with writing ability. Therefore, the null hypothesis was rejected.

\section{Results of Research Hypothesis}

In this part, the researchers tried to present the answer to their study's main question. Based on the results of the data for independent samples t-test for writing scores shown by two raters in pre-test and post-test and the difference between the two groups in their performance on writing tests indicated that the cooperative learning had some effects on the manner of participants' achievement in writing TOEFL essays and there was a significant difference between the experimental and control groups' achievement.

Although the total scores obtained from the tables presented by the raters seem near to each other, but the participants had some difference in separate parts of the essays. Considering each part separately showed the effect of cooperative leaning on certain parts more than other parts of the essays. It, also, showed that there is not any difference especial in writing cooperatively or traditionally. In fact, the results of the data obtained from the posttest showed some similarities and some differences in both learning strategies in both experimental and control groups.

For example, both groups had some problems in applying the correct words in their writing which were categorized as errors [28]. The posttest showed that both groups had some improvements in their performance but this improvement was clearer in the experimental group. But the results were somehow different in the other part which was the amount of the participants' achievement in applying the elements of TOEFL essays basics. The scores show that both groups are nearly the same in applying some TOEFL basics (items) such as: structure, continuity/cohesion, reader orientation, evidential sentences, Conclusion, conclusion summary, and closing.

However, the scores showed that the experimental group had a better performance in applying other TOEFL basics (items) such as: introduction, thesis statement, topic sentences, appropriate registers, and grammar, spel- 
ling, or punctuation (coherence).

In all, the effect of using a special learning style showed itself in the final product which in this study was writing an essay. Even if it was effective in some parts more than others, the results of the final product and its comparison with the first product represents the main effect of using that particular learning or teaching style.

Therefore, the data and the scores obtained from the study results showed that the null hypothesis was rejected. As an answer to the research question, the researcher found out that the application of cooperative leaning had a positive effect on Iranian intermediate students' writing achievement.

\section{Conclusions}

The deployment of cooperative learning for writing TOEFL essays had some certain results which were analyzed via SPSS $\left(18^{\text {th }}\right)$ software. It indicated that the null hypothesis was rejected. The results showed that deployment of cooperative learning had a positive effect on the Iranian intermediate students' writing achievement.

The findings of the study are in agreement with that of Graham \& Perin's study [5] in which shows "a strong impact on learning improving the quality of students' writing”. Since the cooperative learning approach can be viewed from different points, there are some categories of benefits created by cooperative learning such as improving students' learning, retention and academic achievement, and developing and mastering social skills [29].

The scores obtained from the essays written by the participants in the posttest which was based on the grading scale of TOEFL book (2003) represented some major facts about the results of the posttest and its comparison with the pretest. Comparing the scores presented that there was not only the difference between the deployment of the cooperative learning strategies and the traditional method, but it also presented the differences and similarities between the results of both methods.

The items that could be affected by cooperative learning were those which needed some reliance on other resources such as group members or the teacher. They needed to be presented more professionally in order to have a stronger essay. These items could be thesis statement, grammar, spelling, punctuation (coherence), or topic sentences. In fact, it was not important for the students how to learn the first group of items in writing an essay (structure, continuity, etc.) and what method or strategies they followed. They applied the rules or basics they had learned.

In all, although both groups acted similarly in some parts such as using TOEFL format, the cooperative learning showed a more positive effect on the intermediate participants' final writings in the experimental group. Because the participants used their group members' knowledge and skills to present their writing, they had better final writings in comparison with the control group. Of course, different parts of the wittings' analysis showed that they were almost the same in both groups but there were some other parts that indicated the cooperative learning had been more effective for the final result which was the writing scores as a whole. The data obtained from the writings in the pre- and post-tests indicated their better performance. Therefore, the null hypothesis was rejected by the results of the study.

However, this study had its own limitations that were common among all the participants such as the number of and the kind of students' prior experiences, duration of the study, the amount and kind of feedback, and the impact of their native language on the study and product.

However, future studies are suggested to find the effect of age, kind of feedback, and their level of proficiency on the participants' achievement in writing essays.

\section{Acknowledgements}

We would like to express our deepest gratitude to Abbas-Ali Salmani, whose supports, patience and tolerance helped us all the way throughout completing this study.

\section{References}

[1] Folse, K.S. (1994) Intermediate TOEFL Test Practices. The University of Michigan Press, Ann Arbor.

[2] Yang, L. (2010) Teaching English Writing to Develop Creative Thinking Skills for High School Students. HRD Journal, 1, 99-107.

[3] Mandal, R.R. (2009) Cooperative Learning Strategies to Enhance Writing Skill. The Modern Journal of Applied Linguistics, 1, 93-102. 
[4] Hyland, K. (2008) Writing Theories and Writing Pedagogies. Indonesian Journal of English Language Teaching, 4, 91-110. http://www.google.com

[5] Graham, S. and Perin, D. (2007) Effective Strategies to Improve Writing of Adolescents in Middle and Highschools. $1-67$.

[6] Smith, B.L. and MacGregor, J.T. (1992) What Is Collaborative Learning? 1-11. http://www.google.com

[7] Rivers, W.M. (1981) Teaching Foreign-Language Skills. The University of Chicago Press, Chicago.

[8] Harmer, J. (2009) The Practice of English Language Teaching. Pearson Longman, UK.

[9] Shihab, I. (2011) The Effect of Using Cooperative Learning on Jordanian Students with Learning Disabilities' Performance in Mathematics. European Journal of Social Sciences, 25, 251-259.

[10] Apple, M. and Shimo, E. (2010) Using Cooperative Learning Techniques in Your Language Classroom. 73-76. http://www.google.com

[11] Jacobs, G. and Hannah, D. (2004) Combining Cooperative Learning with Reading Aloud by Teachers. International Journal of English Studies, 4, 97-117. http://www.um.es/engphil/ijes

[12] Bowker, N. (2007) Academic Writing: A Guide to Tertiary Level Writing. Massey University, Palmerston North, 1-112. http://www.massey.ac.nz

[13] Richmond, J.N. (2008) Legal Writing: Form and Function. 204-207. http://www.google.com

[14] Onozava, C. (2010) A Study of the Process Writing Approach-A Suggestion for an Eclectic Writing Approach. Research Note, No. 10, 153-163.

[15] Ur, P. (1996) A course in Language Teaching: Practice and Theory. Cambridge University Press, Cambridge.

[16] Hadley, A.O. (2003) Teaching Language in Context. Heinle \& Heinle, Boston.

[17] Becky, L. and Spivey, M., Eds. (2006) What Is the Writing Process? Super Duper Handy Handouts, No. 112, 1-2. http://www.superduperinc.com

[18] Chung, R.G., Lo, C.L., Hsieh, T.H., Chang, W.L. and Hu, Y.C. (2010) Different Cooperative Learning Grouping and Problem-Based Instruction in Promoting Students' Learning Performance. World Transactions on Engineering and Technology Education, 8, 289-294.

[19] Bowen, C.W. (2000) A Quantitative Literature Review of Cooperative Learning Effects on High School and College Chemistry Achievement. Journal of Chemical Education, 77, 116-119. http://dx.doi.org/10.1021/ed077p116

[20] Abdulkarim, R. and Al Jadiry, A. (2012) The Effect of Cooperative Learning Group Division Based on Multiple Intelligences Theory and Previous Achievement on Scientific Thinking Skills Development of Ninth Grade Students in Oman. European Journal of Social Sciences, 27, 553-569. http://www.europeanjournalofsocialsciences.com

[21] Harden, R.M. and Crosby, J.R. (2000) The Good Teacher Is More than a Lecturer: The Twelve Roles of the Teacher. AMEE Education Guide, No. 20, 3-17.

[22] Apple, M.A. (2006) Language Learning Theories and Cooperative Learning Techniques in the EFL Classroom. Doshisha Studies in Language and Culture, 9, 277-301.

[23] Chauhan, S. (2011) The Cooperative Learning: A Way to Establish Individual Accountability in Group Work. Journal of Asian Research Consortium, 268-278. http://www.aijsh.org

[24] Hassaskhah, J. (2005) Cooperative Learning: A Promising Path in Pedagogy. Guilan University Press, Guilan.

[25] Mohamed, A.R., Nair, S., Kaur, T. and Fletcher, L.A. (2008) Using Cooperative Learning Approach to Enhance Writing Skills of Pre-University Students. Educationist, 2, 7-16. http://file.upi.edu.com

[26] Oskoz, A. (2010) Collaborative Writing: Fostering Foreign Language and Writing Conventions Development. Language Learning \& Technology, 14, 51-71. http://www.llt.msu.edu/issues/october2010/elolaoskoz.pdf

[27] Crossly, S.A. and McNamara, D.S. (N.D.) Cohesion, Coherence, and Expert Evaluations of Writing Proficiency. 984-989.

[28] Keshavarz, M.H. (1999) Contrastive Analysis \& Error Analysis. Rahnama Press, Tehran.

[29] Pistorio, M.I. (2010) A Blend of CLIL and Cooperative Learning Creates a Socially Constructed Learning Environment. Latin American Journal of Content \& Language Integrated Learning, 3, 1-10. 